\title{
Article \\ Potassium Alginate Oligosaccharides Alter Gut Microbiota, and Have Potential to Prevent the Development of Hypertension and Heart Failure in Spontaneously Hypertensive Rats
}

\author{
Zhen-Lian Han ${ }^{1,2}$, Meng Chen ${ }^{2}$, Xiao-Dan Fu ${ }^{2}$, Min Yang ${ }^{3}$, Maria Hrmova ${ }^{1}\left(\mathbb{D}\right.$, Yuan-Hui Zhao ${ }^{2, *}(\mathbb{D}$ \\ and Hai-Jin Mou ${ }^{2, *}$ \\ 1 School of Life Science, Huaiyin Normal University, 111 West Changjiang Road, Huai'an 223300, China; \\ ahanzhenlian@163.com (Z.-L.H.); maria.hrmova@adelaide.edu.au (M.H.) \\ 2 College of Food Science \& Engineering, Ocean University of China, 5 Yushan Road, Qingdao 266003, China; \\ chenmeng2838@163.com (M.C.); luna_9303@163.com (X.-D.F.) \\ 3 Yellow Sea Fisheries Research Institute, Chinese Academy of Fishery Sciences, Qingdao 266071, China; \\ minyang89@163.com \\ * Correspondence: zhaoyuanhui@ouc.edu.cn (Y.-H.Z.); mousun@ouc.edu.cn (H.-J.M.); \\ Tel./Fax: +86-532-8203-2400 (Y.-H.Z.); +86-532-8203-2290 (H.-J.M.)
}

Citation: Han, Z.-L.; Chen, M.; Fu, X.-D.; Yang, M.; Hrmova, M.; Zhao, Y.-H.; Mou, H.-J. Potassium Alginate Oligosaccharides Alter Gut Microbiota, and Have Potential to Prevent the Development of Hypertension and Heart Failure in Spontaneously Hypertensive Rats. Int. J. Mol. Sci. 2021, 22, 9823. https://doi.org/10.3390/ijms22189823

Academic Editors: Peter J. Little, Suowen $\mathrm{Xu}$ and Jianping Weng

Received: 22 July 2021

Accepted: 6 September 2021

Published: 11 September 2021

Publisher's Note: MDPI stays neutra with regard to jurisdictional claims in published maps and institutional affiliations.

Copyright: (c) 2021 by the authors. Licensee MDPI, Basel, Switzerland. This article is an open access article distributed under the terms and conditions of the Creative Commons Attribution (CC BY) license (https:// creativecommons.org/licenses/by/ $4.0 /)$
Abstract: Food-derived oligosaccharides show promising therapeutic potential in lowering blood pressure (BP), but the mechanism is poorly understood. Recently, the potential role of gut microbiota (GM) in hypertension has been investigated, but the specific GM signature that may participate in hypertension remains unclear. To test the potassium alginate oligosaccharides (PAO) mechanism in lowering BP and specific microbial signature changes in altering GM, we administered various dosages of PAO in 40 spontaneously hypertensive rats for a duration of six weeks. We analyzed $\mathrm{BP}$, sequenced the $16 \mathrm{~S}$ ribosomal DNA gene in the cecum content, and gathered RNA-seq data in cardiac tissues. We showed that the oral administration of PAO could significantly decrease systolic $\mathrm{BP}$ and mean arterial pressure. Transcriptome analyses demonstrated that the protective effects of developing heart failure were accompanied by down-regulating of the Natriuretic Peptide A gene expression and by decreasing the concentrations of angiotensin II and atrial natriuretic peptide in plasma. In comparison to the Vehicle control, PAO could increase the microbial diversity by altering the composition of GM. PAO could also decrease the ratio of Firmicutes to Bacteroidetes by decreasing the abundance of Prevotella and Phascolarctobacterium bacteria. The favorable effect of PAO may be added to the positive influence of the abundance of major metabolites produced by Gram-negative bacteria in GM. We suggest that PAO caused changes in GM, and thus, they played an important role in preventing the development of cardiovascular disease.

Keywords: blood pressure; potassium alginate oligosaccharides; gut microbiota; heart failure

\section{Introduction}

Hypertension (HTN) has been identified as the leading cause of mortality and disability worldwide because of the high frequency and concomitant risks of cardiovascular diseases (CVD), including stroke and heart failure (HF) [1-3]. Stroke, heart disease, and chronic obstructive pulmonary diseases are the leading causes of death in China [4]. Therefore, sustainable methods for reducing high blood pressure (BP) are urgently needed to combat emerging hypertension in China and worldwide [4,5]. In recent years, researchers found that the lowering BP alginate oligosaccharides include sodium alginate oligosaccharides (SAO) [6,7] and potassium alginate oligosaccharides (PAO) [8], but the mechanism of their action remains unknown.

Alginate oligosaccharides are indigestive in the small intestine but fermented in the colon, where they are colonized by commensal bacteria, which are known as gut microbiota (GM) [9]. Accumulated evidence suggested that GM were associated with 
various diseases, such as colorectal cancer, liver cirrhosis, arthritis, type 2 diabetes, and atherosclerosis [10-14]. Emerging evidence supported that the changes in the intestinal flora could regulate BP $[15,16]$, and gut dysbiosis is an important causal factor for the pathogenesis of HTN [17]. Marques et al. reported that a high-fiber diet could prevent the development of HTN via changing GM in DOCA-Salt hypertensive mice [18]. Hidalgo et al. suggested that an extra virgin olive oil-enriched diet also reduced HTN-related profile changes of GM in spontaneously hypertensive rats (SHR) [19]. Captopril, an angiotensinconverting enzyme inhibitor (ACEi), could influence the brain-gut axis to maintain the antihypertensive effect in SHR [20] but have adverse side effects, such as the reduced renal function and angioedema [21]. Regulation of intestinal microbiota through diet interventions may be a new strategy for the nutritional treatment of HTN [22].

Studies showed that oligosaccharides could also have beneficial activities to human/animal health through interaction with gut microbiota [23]. Alginate oligosaccharides improve lipid metabolism and inflammation by modulating Akkermansia muciniphila, Lactobacillus reuteri, and Lactobacillus gasseri in high-fat diet fed mice and increase the "beneficial" microbes such as Leuconostocaceae in mice with small intestinal mucositis [24,25]. In our previous study based on our data of the $16 \mathrm{~S}$ ribosomal DNA (rDNA) gene sequencing, we found out that alginate oligosaccharides altered the microbiota composition and decreased the ratio of Firmicutes and Bacteroidetes in pig fecal bacteria [26]. Therefore, the specific microbial signature associated with HTN and the mechanism lowering BP need to be revealed after interventions with alginate oligosaccharides.

To address the questions specified above, we performed $16 \mathrm{~S}$ rDNA gene sequencing of cecum samples from 30 SHR of Vehicle, PAO, KCl, and Captopril-treated diets. The cardiac RNA-seq data were also analyzed and pointed at the crucial differential gene expression of associated genes to reveal the mechanism of PAO in lowering BP.

\section{Results}

\subsection{HPAO and LPAO Decreased BP in SHR}

The SBP, DBP, and MAP parameters were measured to assess the effect on BP during the 6-week period (Figure 1). In Vehicle, SBP increased along within three weeks' administration. From week 4 to 6 , SBP was stable, and a similar trend was observed for MAP, while DBP slowly decreased. After 6-week administration, SBP increased by more than $40 \mathrm{mmHg}$ in total. This agreed with the previous study of SHR [27].

In the present study, HPAO decreased SBP significantly compared to Vehicle on week 3 (mean \pm SD $189.8 \pm 5$ vs. $209 \pm 16, p=0.052$, Figure 1A). Furthermore, Figure 1A showed that the administration of HPAO significantly decreased SBP from week 4 to week 6 versus the Vehicle-treated group (mean \pm SD $191.7 \pm 7 \mathrm{mmHg}$ vs. $209 \pm 9 \mathrm{mmHg}$, $188.9 \pm 5 \mathrm{mmHg}$ vs. $208 \pm 8 \mathrm{mmHg}, 191.7 \pm 7 \mathrm{mmHg}$ vs. $211 \pm 8 \mathrm{mmHg} ; p<0.05, p<0.01$ and $p<0.01$, respectively, Figure 1A). MAP was mirrored by the similar decreases on weeks 5 and 6 (Figure 1C). These data showed that HPAO vs. Vehicle decreased SBP and MAP. The oral administration of LPAO at a dose of $300 \mathrm{mg} / \mathrm{kg}$ also decreased SBP from week 4 to week $6(192.2 \pm 14 \mathrm{mmHg}, 187.8 \pm 12 \mathrm{mmHg}, 191.5 \pm 17 \mathrm{mmHg}, p<0.05$, $p<0.01$ and $p<0.01$, respectively; Figure 1). Similar decreases were found in levels of MAP with LPAO on weeks 5 and 6 (Figure 1C). To elucidate the potential effect of potassium, we treated SHRs at the dose of $114 \mathrm{mg} / \mathrm{kg} \mathrm{KCl}$. We found that $114 \mathrm{mg} / \mathrm{kg} \mathrm{KCl}$ did not significantly change BP in the SHR model, suggesting that phenotypic differences may have been caused by the alginate oligosaccharides in SHR. Captopril significantly reduced SBP and MAP compared to the Vehicle-treated group from week 1 to week 6 , and DBP decreased relatively weakly similar to HPAO and LPAO (Figure 1A-C). 
A

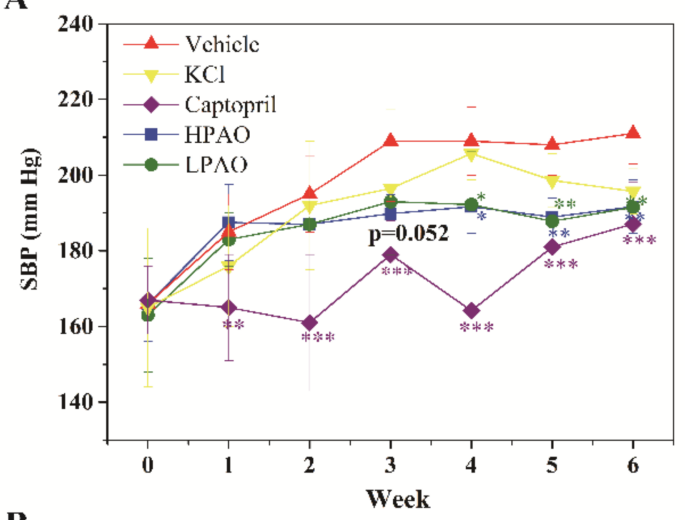

B

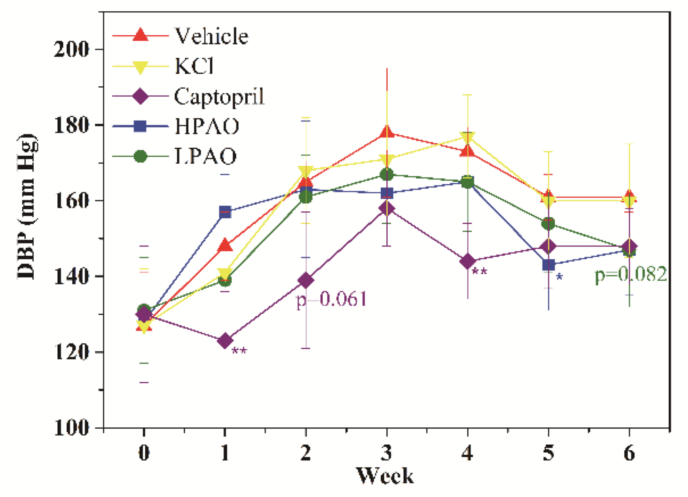

C

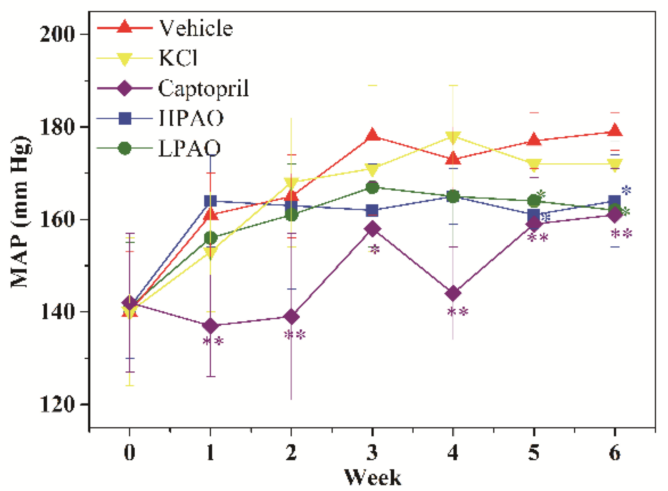

Figure 1. Vehicle, $\mathrm{KCl}$, Captopril, HPAO, and LPAO modulate (A) SBP, (B) DBP, and (C) MAP in the SHR model. Values are mean $\pm \operatorname{SD}(n=8) .{ }^{*} p<0.05,{ }^{* *} p<0.01,{ }^{* * *} p<0.001$ vs. Vehicle.

\subsection{HPAO Interventions Attenuated Cardiac Fibrosis}

Perivascular and interstitial cardiac fibrosis were observed in SHR after six weeks (Figure 2). The perivascular volume fraction decreased from $1.76 \pm 0.13 \%$ in the Vehicletreated group to $1.04 \pm 0.17 \%$ in the HPAO group $(p=0.081)$. The interstitial volume fraction also decreased in SHR from the values of $1.34 \pm 0.34 \%$ in the Vehicle-treated group to $0.42 \pm 0.15 \%$ in the HPAO group $(p=0.050)$. Again, Captopril $(0.45 \pm 0.14 \%, p=0.057)$ attenuated the perivascular and interstitial volume fraction but could not be significantly compared to the Vehicle-treated group (Figure 2B,C). These data indicated that the 6-week administration of HPAO could attenuate interstitial cardiac fibrosis, which could be an important therapeutic target for HF [28]. 

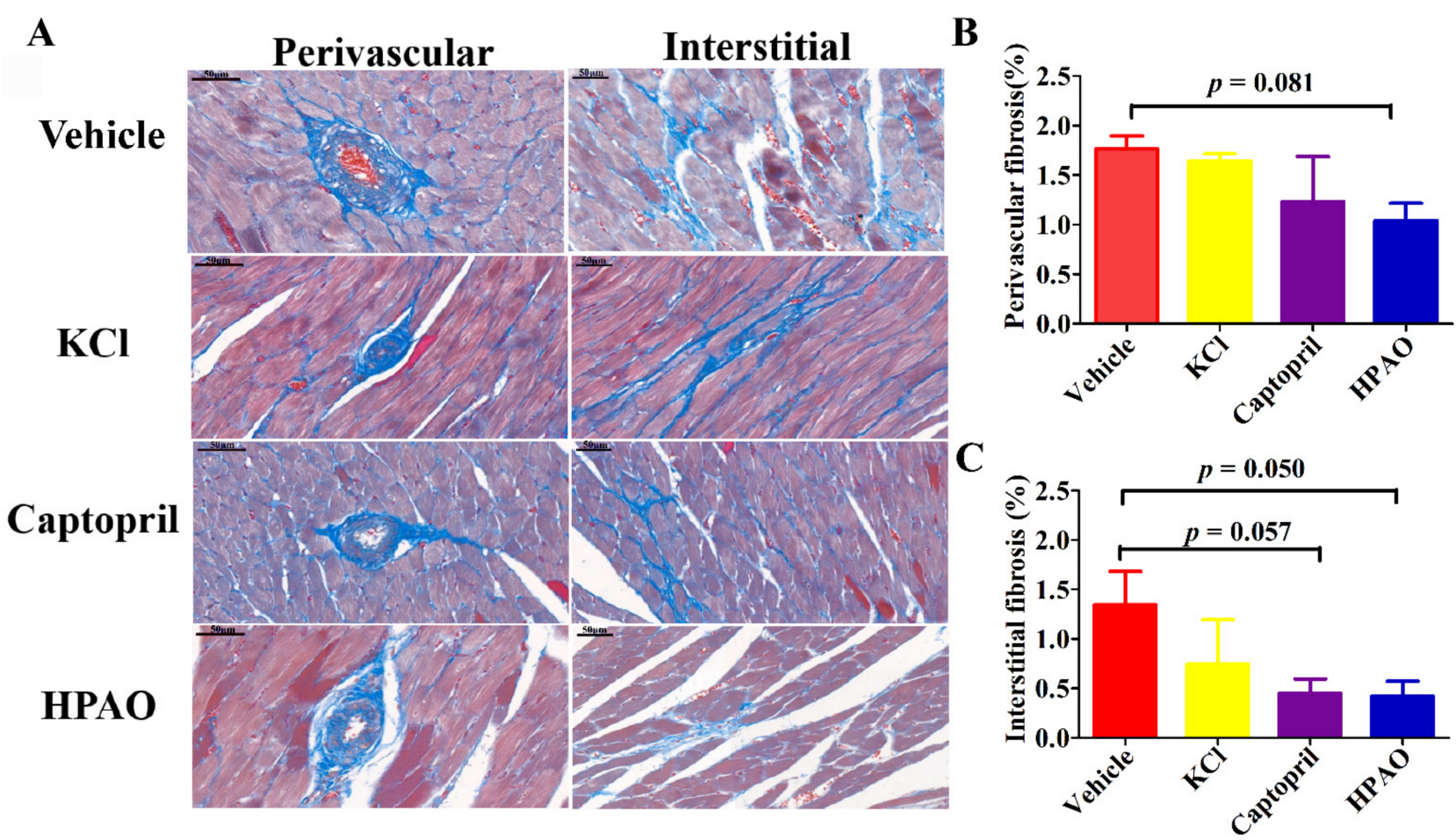

Figure 2. HPAO reduces cardiac fibrosis in SHR. (A) Representative histological images of obtained via Masson trichrome staining for each treatment (scale bar $=50 \mu \mathrm{m}$ ). Compared to Vehicle, HPAO caused a mild decrease in (B) cardiac perivascular fibrosis, while $(\mathbf{C})$ interstitial fibrosis was significantly reduced by HPAO. Values are mean \pm SEM. One-way ANOVA with Least Significant Difference (LSD) adjustment for multiple comparison was used.

\subsection{Cardiac Transcriptome}

To support the underlying mechanism, transcriptome profiling of cardiac samples from the HPAO, Captopril, $\mathrm{KCl}$, and Vehicle-treated groups was carried out. As shown in Figure 3A-D, Principal Component Analysis (PCA) showed that the $\mathrm{HPAO}, \mathrm{KCl}$, and Captopril-treated groups differed mildly compared to the Vehicle-treated group (Figure $3 \mathrm{~A}$ ). In the heart, 32,883 genes were examined in total. Of these, 563 genes were differentially expressed in the HPAO-treated group ( $p$-value $<0.05$, Table S1), while 626 genes were differentially expressed in the Captopril-treated group (Table S2) compared to the Vehicletreated group. Sixteen genes were shared between the HPAO and Captopril-treated groups (Figure 3C), whereby the Nppa gene was down-regulated; the expression of the Nppa gene is mostly associated with hypertrophic ventricle [29], HTN [30], and HF [31]. On the other hand, the up-regulated genes thought to have a role in albuminuria [32] and cardiac cell death [33] were Zinc finger protein 622 (Zfp622) and Dihydropyrimidinase like 4 (Dpysl4), respectively (Figure 3B). Additionally, four other genes were markedly differentially expressed between the Vehicle-treated and HPAO groups (Figure 3D); these genes are the Paired mesoderm homeobox protein 2 (Prrx2) and the T-box transcription factor 6 (Tbx6) that are associated with cell migration [34] and cardiomyocyte regeneration, respectively [35]. On the other hand, Beta-defensin 1 (Defb1) and the C-C motif chemokine ligand 1 (Ccl1) are related to HTN.

Differential expressed genes (DEGs) between the HPAO and Vehicle groups were further analyzed using the Gene Ontology (GO) bioinformatics resource, whereby cellular components and biological process involved in DEGs in the Vehicle vs. HPAO-treated groups were analyzed (Tables S3 and S4). The molecular functions of the DEG entries were classified into ten categories, including binding, catalytic activity, transporter activity, nucleic acid binding transcription factor activity, signal transducer activity, and molecular transducer activity (Figure S1A). Among them, DEG entries related to binding, catalytic activity, and transporter activities accounted for $49 \%, 23 \%$, and $8 \%$, respectively. Forty- 
eight KEGG pathways enriched by DEG entries between the HPAO and Vehicle-treated groups are summarized (Table S5). As expected, seven significantly enriched disease hallmark pathways that were identified (Figure S1B), including MAPK, mTOR, and the chemokine signaling pathway, are associated with HTN-induced renal damage [36], cardiac hypertrophy [37], and vascular remodeling [38], respectively. Shigellosis and Legionellosis were also significantly enriched by HPAO.

A

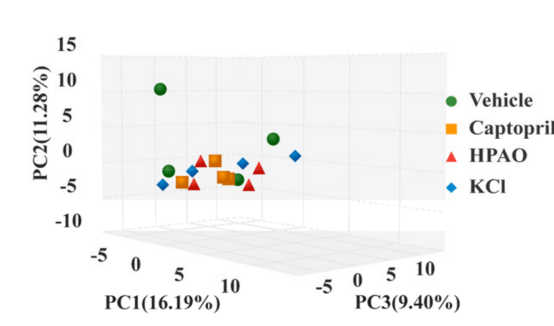

C

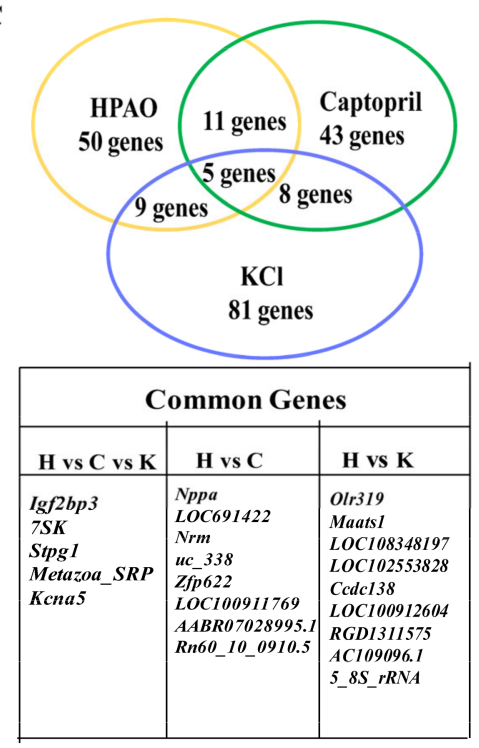

B

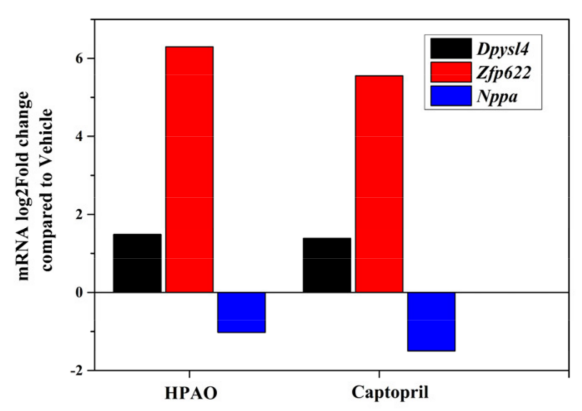

D

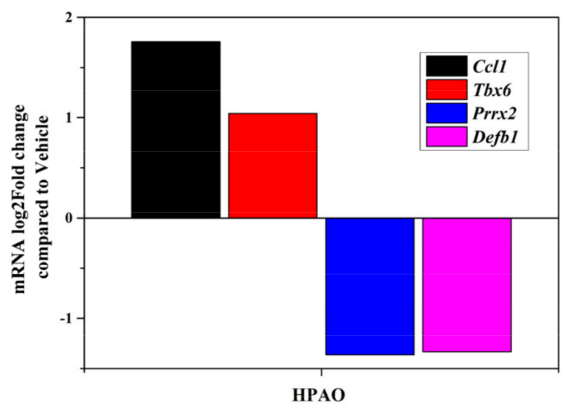

Figure 3. Cardiac transcriptome of SHR fed with $\mathrm{HPAO}$, Captopril, $\mathrm{KCl}$, and Vehicle diets. (A) PCA analysis, (B) common genes between HPAO, Captopril, and $\mathrm{KCl}$ compared to the Vehicle group, (C) differentially expressed common genes between the HPAO and Captopril groups, and (D) differentially expressed genes in the HPAO group.

The Nppa gene participated in ten pathways. Five out of the 10 signaling pathways were up-regulated by Captopril, such as aldosterone synthesis and secretion and the CAMP, thermogenesis, and oxytocin signaling pathways (Figure S2). The oxytocin signaling pathway was also up-regulated in the HPAO group (FDR $q$-value $=0.78$ ). To understand which pathway was specifically affected by the Nppa gene, known regulators of associated pathways are summarized (Figure 4A). To verify the hub of the Nppa gene expression, the mRNA expression level of Nppa (Figure 4B) and the ANP protein level (Figure 4C) were analyzed. To verify which of the downstream regulators in these pathways change, the plasma level of AngII was examined (Figure 4D). These data suggested that HPAO could down-regulate the mRNA level of Nppa and reduce the synthesis of ANP and AngII at the protein levels in the plasma, as these levels differed significantly (Figure $4 C, D, p<0.05$ ) between the HPAO and Vehicle-treated groups. 
A

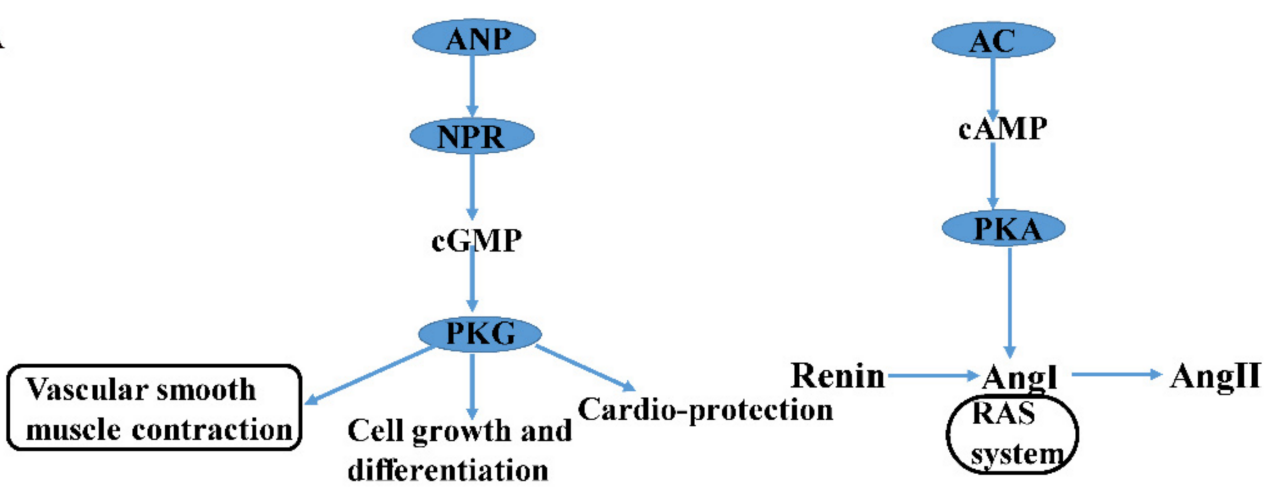

B

platelet inhibition
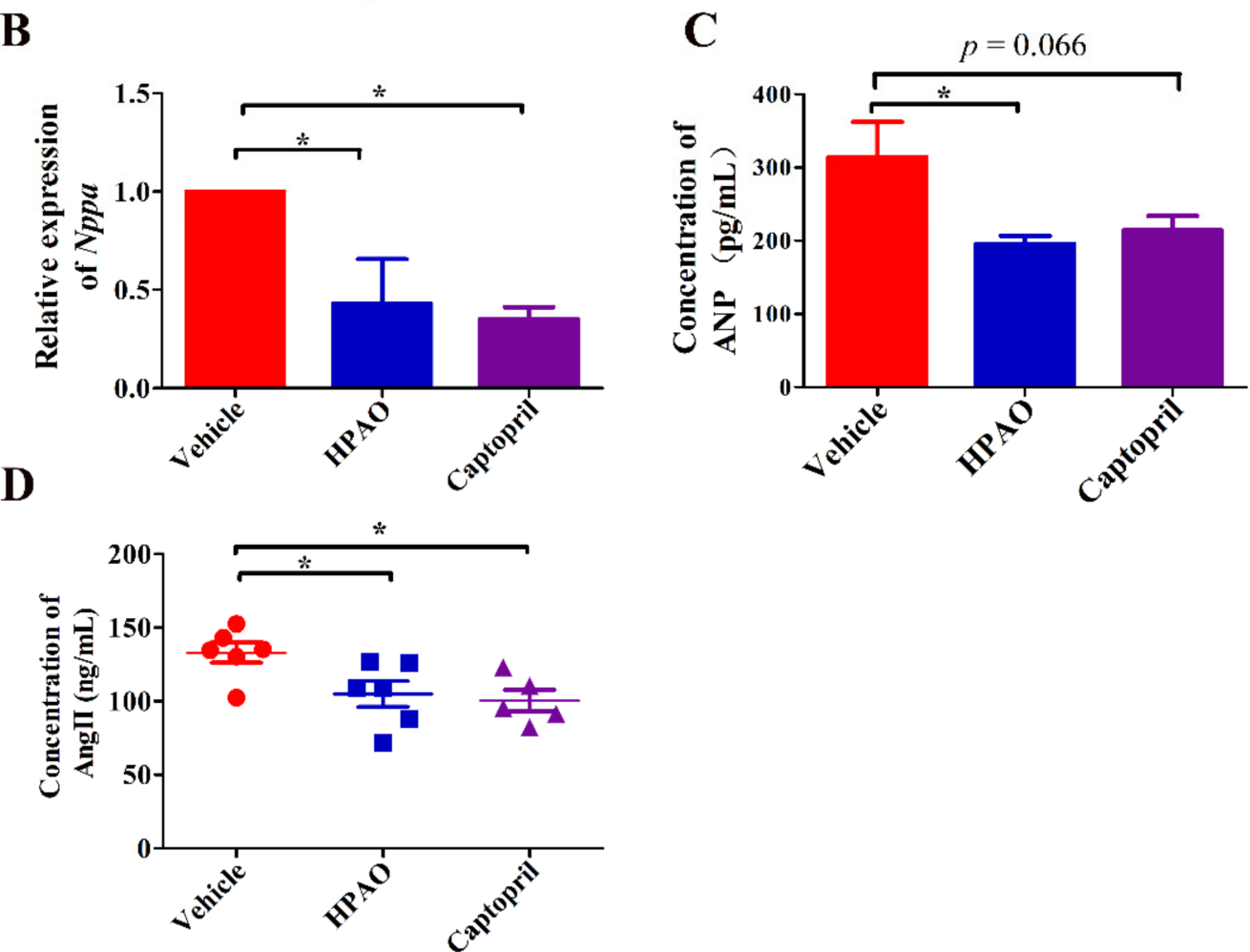

Figure 4. The influence of changes in Nppa expression level on the pathway. (A) Summarized pathways related to cardia, where Nppa is involved, (B) mRNA levels of Nppa expression, concentrations of (C) ANP and (D) AngII. Data were mean \pm SEM (Nppa, ANP, $n=3)$. Significance was accepted at * $p<0.05$. One-way ANOVA with LSD adjustments for multiple comparison was used.

\subsection{PAO Altered Gut Microbiota Dysbiosis in SHR}

To investigate if PAO alters the GM structure and composition in SHR, we sequenced the $16 \mathrm{~S}$ rDNA gene in the cecum content. Through alpha diversity analyses, Shannon, Simpson, Ace, and Coverage indices were compared between $\mathrm{PAO}, \mathrm{KCl}$, and Captopril with Vehicle-treated groups. The Ace Index was significantly increased $(p=0.03)$ between the HPAO and Vehicle groups (Table S6 and Figure S3). The Shannon Index was observed to be significantly different $(p=0.076)$ between the $\mathrm{KCl}$ - and Vehicle-treated groups. The data of the $\beta$ diversity analysis, PCA, and the Principal Coordinates Analysis (PCoA) showed that HPAO and LPAO both altered the composition of GM significantly compared to the $\mathrm{KCl}$, Captopril, and Vehicle diets (Figure 5A). This was supported by the differences in the relative abundance in bacterial phyla (Figure S4A), families (Figure S4B), and at genera levels (Figure S4C) between the groups. At the phylum level, the dominant bacteria in SHR were Firmicutes and Bacteroidetes (Figure S4A), representing up to $95 \%$ of the 
total amount of bacteria. The ratio of Firmicutes and Bacteroidetes, as a marker of gut dysbiosis, was five-fold higher in SHR compared to that in Wistar-Kyoto (WKY) rats [14]; this ratio was significantly lowered to nearly one-half in the HPAO, LPAO, and Captopril group compared to the Vehicle-treated group $(p<0.05)$ (Figure 5B). At the family level, the dominant bacteria (relative abundance $>0.01$ ) were Lachnospiraceae, Ruminococcaceae, Prevotellaceae, Bacteroidales_S24-7_group, Lactobacillaceae, Bacteroidaceae, Christensenellaceae, Acidaminococcaceae, and Verrucomicrobiaceae (Figure S4B). In the top 24 families, the relative abundance of Bacteroidales_S24-7_group, Rikenellaceae, and Bacteroidaceae that belong to Bacteroidetes was significantly higher in the PAO group compared to the Vehicle-treated group, while the relative abundance of Acidaminococcaceae (classified in Firmicutes) was significantly lower both in the HPAO and Captopril groups $(p<0.05)$ (Figure 5C). The relative abundance of the Clostridiales_vadinBB60_group that belongs to Firmicutes was significantly higher in the PAO groups compared to the Vehicle-treated group, but the relative abundance of the Clostridiales_vadinBB60_group was less than 0.0010. Therefore, the contribution of the Clostridiales_vadinBB60_group to the relative of abundance of Firmicutes was small. At the top 40 genus level, the relative abundance of Prevotella_9 (0-0.3) and Phascolarctobacterium $(<0.05)$ was significantly decreased in the HPAO group compared to the Vehicle-treated group $(p<0.05, p=0.005$, respectively), while Prevotellaceae_NK3B31_group and Ruminococcaceae_norank were increased significantly $(p<0.05, p=0.000$, respectively, Figure 5D). At the species level, the relative abundance of Bacteroides uniformis was high in the HPAO and LPAO groups, but this bacterium had low levels in the $\mathrm{KCl}$, Captopril, and Vehicle groups ( $p=0.093$, Figure 5E). The abundance of Lactobacillus intestinalis was significantly higher in the LPAO group compared to the Vehicle-treated group ( $p=0.038$, Figure 5E). Furthermore, changes in bacteria between the PAO, Captopril, and Vehicle groups were analyzed by Linear discriminant analysis effect size (LEfSe) (Figure S5 and Table S7). The abundance of Coriobacteriaceae was reported to show a significant increase in hypertensive rats fed on the high-fat diet [39]; the abundance was higher in the Vehicle-treated group compared to those in the HPAO, LPAO, and Captopril groups. These data indicated that PAO could alter the relative abundance of Firmicutes and Bacteroidetes to modify gut dysbiosis, which was supported by changes of the relative abundance at the family, genus, and species levels.

\section{5. $16 \mathrm{~S}$ rDNA Gene Function Analysis}

To understand how they operate, $16 \mathrm{~S}$ rDNA gene sequence data were further analyzed by PICRUSt analysis to predict the function of PAO. In total, 196 KEGG pathways and 25 Clusters of Orthologous Groups (COG) functional categories were predicted from the Operational Taxonomic Unit (OTU) dataset. We observed that four KEGG pathways were particularly affected by the PAO (Figure 6). Lipoic acid metabolism, non-homologous end-joining, and proximal tubule bicarbonate reclamation were significantly enhanced by LPAO $(p<0.05$, Figure 6 A,C,D). It has been previously reported that lipoic acid, an antioxidant, could lower BP in SHR [40] and improve the endothelial function in metabolic syndrome patients, which is associated with increased Ang II activity [41]. These data illustrated that an increase in the relative abundance of the $16 \mathrm{~S}$ rDNA gene may impact the lipoic acid metabolism, which is evidence that PAO could lower BP. 
A

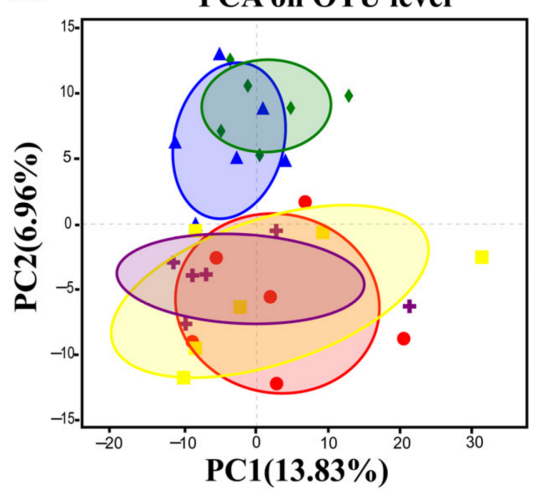

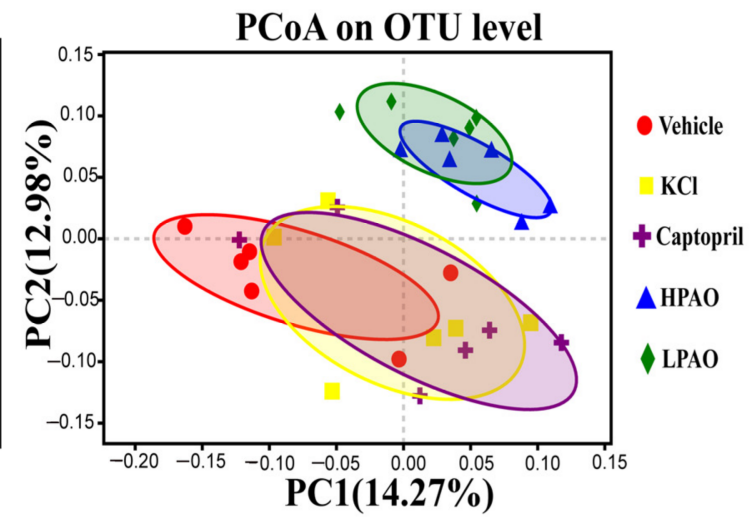

B

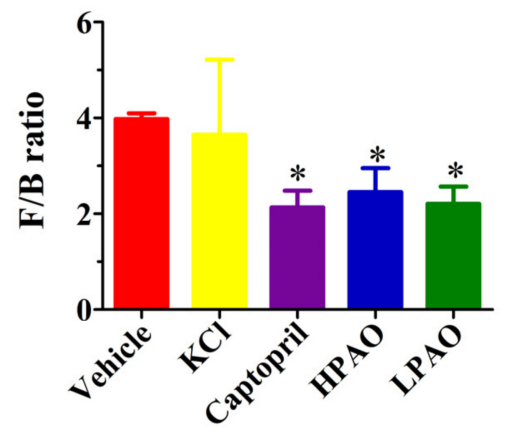

C
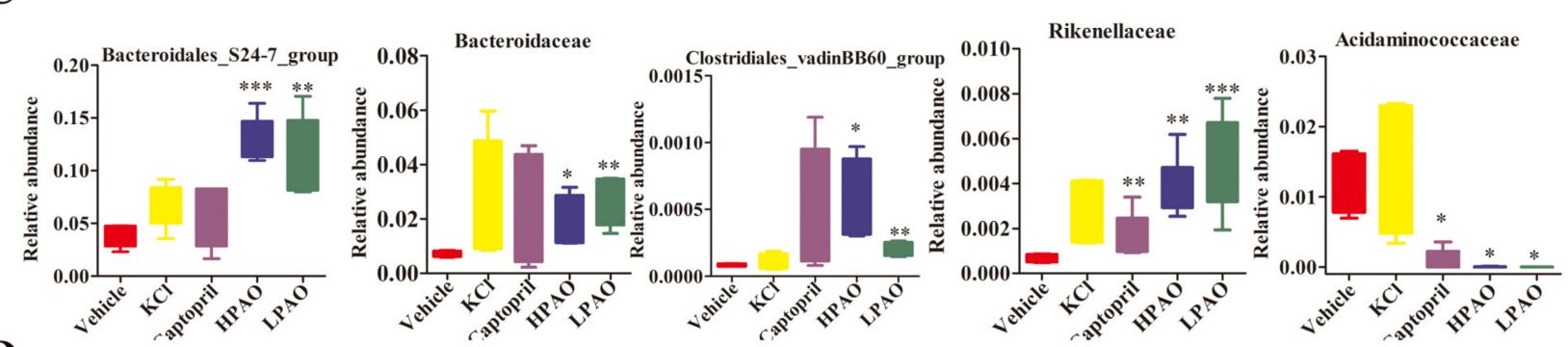

D
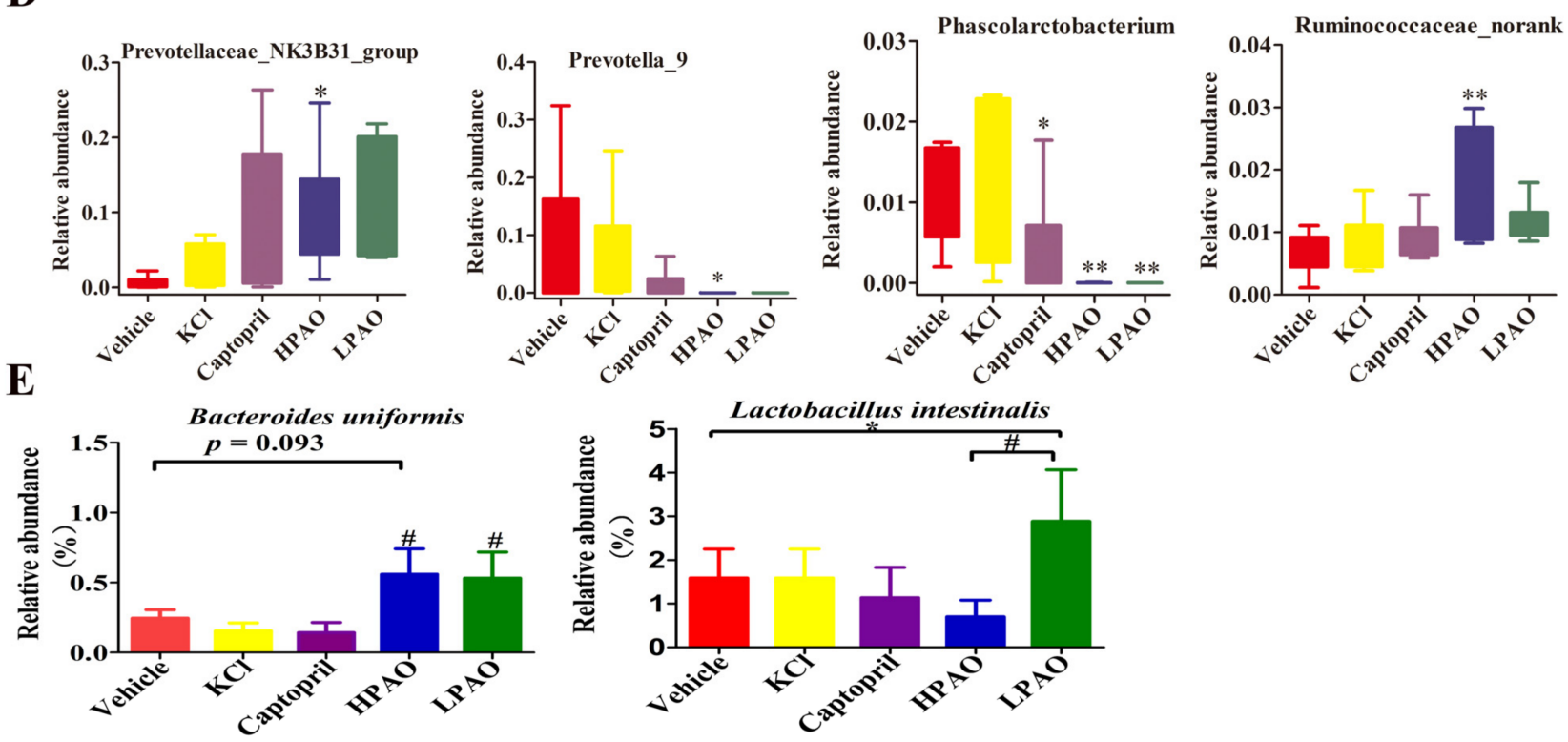

Figure 5. The effect of Vehicle, $\mathrm{KCl}$, Captopril, HPAO, and LPAO supplementation in GM. (A) HPAO and LPAO alter the composition of GM significantly compared to the $\mathrm{KCl}$, Captopril, and vehicle groups; the data indicate unweighted UniFrac PCA and unweighted UniFrac PCoA. (B) The Firmicutes to Bacteroidetes ratio, as a marker of gut dysbiosis, is significantly lower in HPAO, LPAO, and Captopril $(p<0.05)$. One-way ANOVA with Tukey's adjustments for multiple comparison was used. (C) The relative abundance of significant families in the top 24 entries between the Vehicle, $\mathrm{KCl}, \mathrm{Captopril,} \mathrm{HPAO}$, and LPAO groups. Statistical analysis was performed using $t$-test. (D) Relative abundance of significant genera in top 40 between the Vehicle, $\mathrm{KCl}$, Captopril, HPAO, and LPAO groups. One-way ANOVA with LSD adjustments for multiple comparison was used. (E) PAO had higher levels of bacteria from the Bacteroides uniformis and Lactobacillus intestinalis species than the Vehicle group $(p=0.093)$. Data were mean $\pm \mathrm{SEM}^{*} p<0.05,{ }^{* *} p<0.01,{ }^{* * *} p<0.001$ vs. Vehicle, ${ }^{*} p<0.05$ vs. $\mathrm{KCl}$ and Captopril groups, respectively. One-way ANOVA with LSD adjustments for multiple comparison was used. 
A

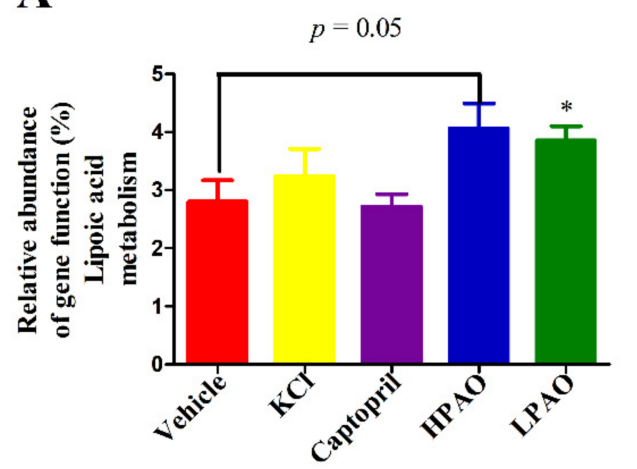

C

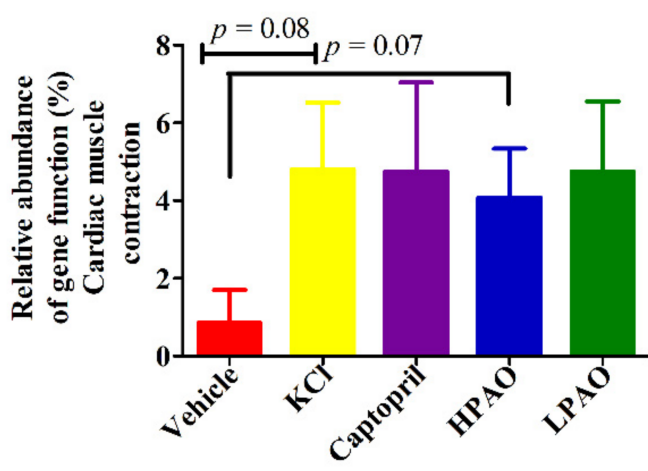

B

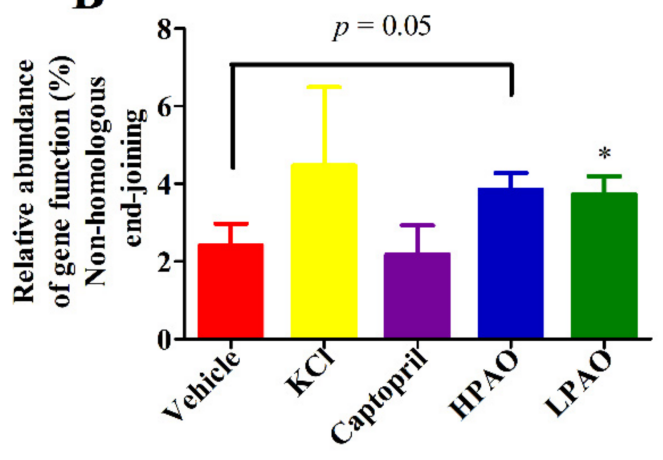

D

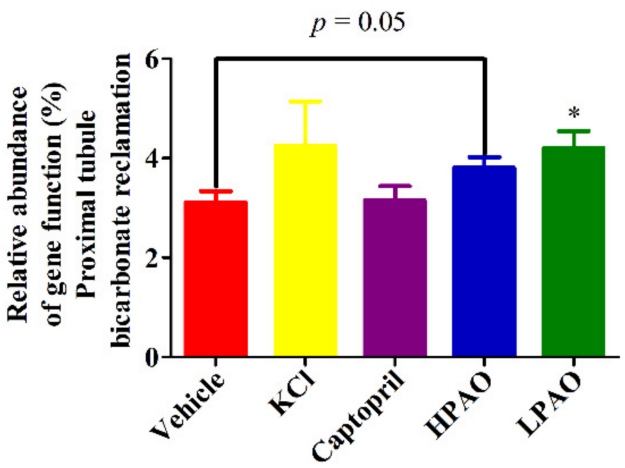

Figure 6. Selected biological pathways and functional categories of GM displaying differences in the relative abundance in GM. Relative abundance of the gene function (\%). (A) Lipoic acid metabolism, (B) Non-homologous end-joining, (C) Cardiac muscle contraction, and (D) Proximal tubule bicarbonate reclamation. Data were mean \pm SEM. Statistical analysis was performed using $t$-test $*<0.05$ vs. Vehicle.

\section{Discussion}

In the present study, we investigated if HPAO could lower BP and alter the GM structure and composition to be able to prevent the cardiac effects of CVD. As expected, we found that HPAO could lower BP in the SHR model. These findings were similar to those obtained with SAO and PAO, whereas these preparations could attenuate BP in a genetic rat model of human HTN and deoxycorticosterone acetate (DOCA) salt-induced HTN, respectively [6,8]. Furthermore, we found that HPAO was able to reduce cardiac fibrosis, while we did not observe any significant changes in the $\mathrm{KCl}$ group. A previous study [42] indicated that alginate oligosaccharides could alleviate the myocardial reperfusion injury, in part by inhibiting oxidative stress and endoplasmic reticulum stress-mediated apoptosis. However, in this study, we also observed an alternative molecular mechanism by analyzing the data of the cardiac transcriptome in the HPAO, Captopril, and Vehicle-treated groups. The Nppa gene, encoding for the ANP, is involved in regulation of the cAMP signaling pathway and renin-angiotensin system (RAS), while cAMP signaling could ameliorate HTN [43], where the cardiac myocyte cAMP level and the myocardial contractile function are regulated by the phosphodiesterase 3A [44]. Ang II could influence the BP level through regulating the vascular contraction and relaxation [45]. ANP is supposed to be beneficial in heart failure and hypertension [46]. However, in this study, the concentration of Ang II and ANP were decreased compared to the Vehicle group in SHR. Soualmia H et al. [47] reported that AngII can affect the changes of ANP by the NO in SD rats. It is known that the concentration of AngII is a key mediator in hypertension [48]. Therefore, as HPAO could lower BP and prevent the development of HF in the SHR model, we suggested that 
HPAO may regulate the expression of Nppa and then regulate the cAMP signaling pathway and RAS.

HPAO could also significantly enriched the Shigellosis and Legionellosis signaling pathways (Figure S1). LPS, a component of the outer membrane of the Gram-negative bacteria, is involved in the Legionellosis signaling pathway. For this reason, we determined plasma LPS. The concentration of plasma LPS was decreased by HPAO after a six-week intervention compared to Vehicle (Figure 7A) and significantly influenced the populations of bacteria in the top ten genus distribution $(p=0.025)$ (Figure 7B). Notably, as observed in the present study, the relative abundance of the Gram-negative bacteria, such as Phascolarctobacterium and Prevotella_9 decreased nearly to zero (Figure 5D), and this was positively correlated with LPS and SBP, respectively (Figure 7C) after HPAO intervention. Higher relative abundances of Gram-negative bacteria including Phascolarctobacterium and Prevotella were related to the higher BP in HTN patients $[17,49]$. In the hypertensive state, more gut permeability was present and LPS translocated from the gut to the circulation and induced systemic inflammation, which is linked to hypertension [50,51]. In addition, LPS is also known as the mechanistic biomarker of CVD [52]. Our finding demonstrated that HPAO decreased BP, which is associated with modifying gut dysbiosis, lowering the abundance of Prevotella_9 and Phascolarctobacterium, and reducing LPS metabolites. We suggested that further studies are needed to verify if the oral administration of HPAO could lower BP by modulation of the abundance of Prevotella and Phascolarctobacterium.

A
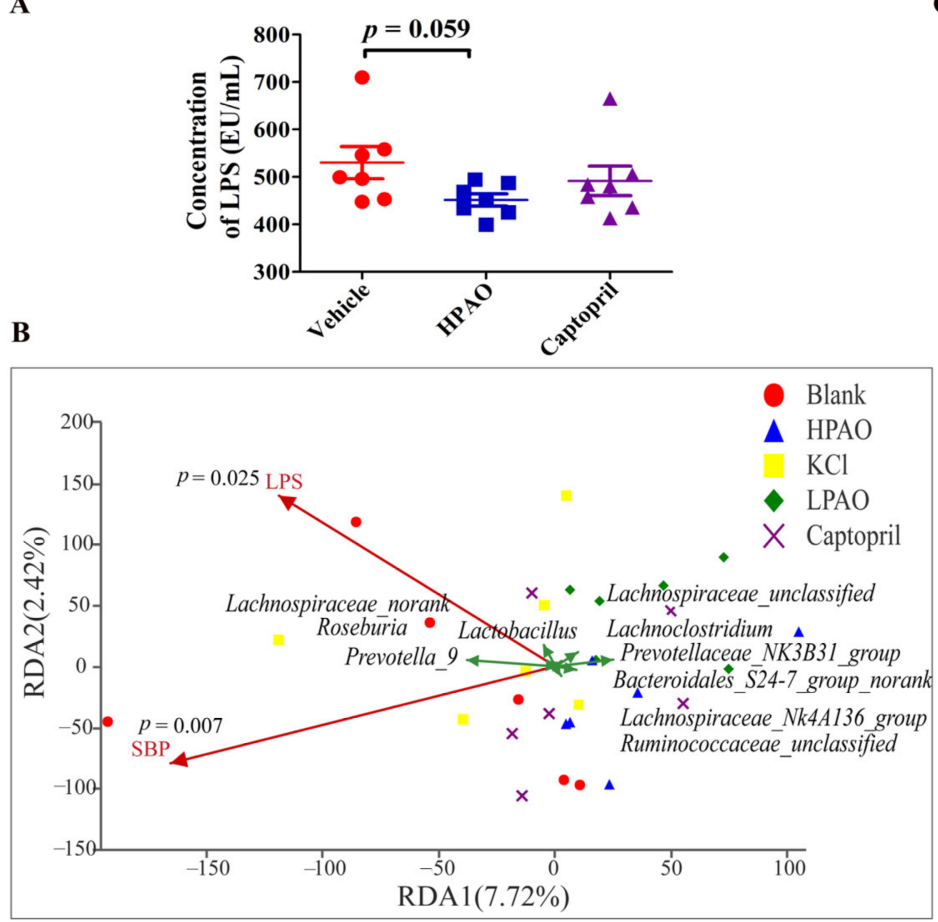

C

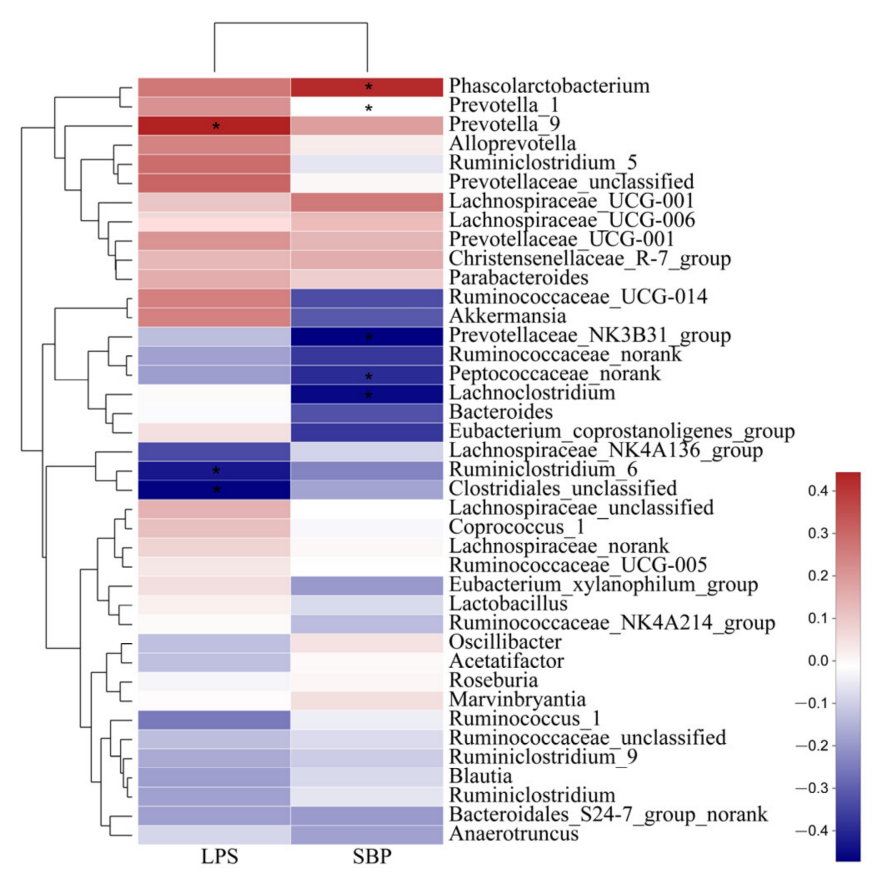

Figure 7. Correlation analysis between changes of plasma LPS level, intestinal bacteria, and SBP. (A) The concentration of LPS in Vehicle, HPAO, and Captopril. Data were mean \pm SEM ( $t$-test, $n=7)$. (B) The redundancy analysis between LPS, SBP, and ten taxa. (C) The correlation analysis between LPS, BP, and GM in the top twenty entries at the family and genera levels $\left({ }^{*} p \leq 0.05\right)$.

To understand the role of another metabolite of GM, cecum short-chain fatty acids (SCFAs) were measured (Figure S6). As for SCFAs changes, compared to Vehicle, no significant differences were observed in acetic acid, propionic acid, and butyric acid levels in the HPAO group, which is consistent with the results of a previous report in WKY and SHR [27]. These analyses also provided evidence that the changes of the GM composition correlated with the development of hypertension. In the present study, compared to Vehicle, the levels of propionic acid-producing bacteria, Bacteroides uniformis, did not differ 
significantly in the HPAO group (Figure 5E). However, we could not rule out that SBP changes could correlate with the concentration of SCFAs. Several studies reported that acetate and propionate levels could attenuated cardiac fibrosis $[18,53]$. Notably, the level of the lactic acid level was raised after six weeks in the HPAO group after administration. Levels of Lactobacillus intestinalis were higher in the LPAO group compared to Vehicle. Candesartan may attenuate chronic low-grade inflammation by counteracting decreased levels of lactic acid-producing genus Lactobacillus [54]. Levels of SCFA-producing microbes were negatively correlated with fecal SCFA levels [53], and we also found the higher concentration of lactic acid and the lower abundance of Lactobacillus in the HPAO group. In the future, it will be necessary to undertake intervention studies with oral SCFA that could help to elucidate the pathways or effects of these metabolites on BP [55].

It is also important to point out that HPAO decreased BP by regulating the ratio of Firmicutes to Bacteroidetes, lowering the relative abundance of Prevetolla_9 and Phascolarctobacterium, and reducing the plasma LPS level. Furthermore, HPAO attenuated cardiac fibrosis, possibly by regulating the expression of Nppa, the cAMP signaling pathway, and RAS to prevent the development of CVD.

\section{Materials and Methods}

\subsection{Preparation of $P A O$}

PAO was prepared by the enzymatic hydrolysis of potassium alginate (Qingdao Hyzlin Biology Development Co. Ltd., Qingdao, China) method as described previously with slight modifications [26]. In brief, $5 \%(w / v)$ potassium alginate was mixed with the alginate lyase $(28 \mathrm{U} / \mathrm{mL})$ and incubated for $6 \mathrm{~h}$ at $37^{\circ} \mathrm{C}$ to prepare PAO. After hydrolysis, the sample was centrifuged $\left(23,275 \times g, 20^{\circ} \mathrm{C}, 15 \mathrm{~min}\right)$, and the final product was obtained through a three-fold precipitation of the supernatant by $95 \%(v / v)$ ethanol. The chemical composition and the molecular mass of the hydrolysate (Table S8) were determined using the previously described method [26].

\subsection{Animal Model and Treatment}

The experimental protocol was approved by the Committee on the Ethics of Animal Experiments of Ocean University of China (Approved protocol ID SCKK 2016-0011). SHR (body weight varied between 175 and $215 \mathrm{~g}$, Male, 8 weeks old) were obtained from Vital River Laboratory Technology Co. Ltd. (Beijing, China). During experiments, rats were housed in a room maintained under the $12 \mathrm{~h}$ light/dark cycle at $22{ }^{\circ} \mathrm{C}$. Rats had free access to fresh water and were fed the Maintenance Purified Diet (GB 14924.3-2010) ad libitum throughout experiments. Rats were randomly assigned to five groups $(n=8)$ : Vehicletreated group (Vehicle), $600 \mathrm{mg} / \mathrm{kg}$ PAO-treated group (HPAO), $300 \mathrm{mg} / \mathrm{kg}$ PAO-treated group (LPAO), $114 \mathrm{mg} / \mathrm{kg} \mathrm{KCl}$-treated group $(\mathrm{KCl})$, and $10 \mathrm{mg} / \mathrm{kg}$ Captopril-treated group (Captopril) that were refreshed twice per week. Vehicle (volume-matched distilled water), $\mathrm{HPAO}, \mathrm{LPAO}, \mathrm{KCl}$, and Captopril were administered orally once daily for six weeks. Systolic blood pressure (SBP), diastolic blood pressure (DBP), and mean arterial pressure (MAP) were measured using the tail-cuff method on the rat blood pressure monitoring system (BP-2010A System, Softron, Beijing, China) every week. After six weeks of treatment, all rats were anaesthetized and sacrificed by ether. Blood samples were collected and centrifuged $\left(1000 \times g, 20 \mathrm{~min}, 4^{\circ} \mathrm{C}\right)$ to isolate blood cells. Rats were weighed and their SBP was measured every week; the body weight changes are shown in Figure S7. Concentrations of plasma lipopolysaccharide (LPS), angiotensin II (Ang II), and the atrial natriuretic peptide (ANP) were determined using the commercial ELISA Kits (Shanghai Elisa Biotech Co., Ltd., Shanghai, China) according to the manufacturer's protocols.

\subsection{Gut Microbiome}

The cecum contents were collected rapidly and stored at $-80{ }^{\circ} \mathrm{C}$. Microbial DNA was extracted from six samples per group using the E.Z.N.A. ${ }^{\circledR}$ soil DNA Kits (Omega Biotek, Norcross, GA, USA) according to the manufacturer's protocols. DNA concentration 
and purity were determined by NanoDrop 2000 (Thermo fisher Scientific Inc., Wilmington, NC, USA), and DNA quality was checked on $1 \%(w / v)$ agarose gels. The V3-V4 hypervariable regions of the bacteria $16 \mathrm{~S}$ rDNA gene were amplified using the forward $5^{\prime}$-ACTCCTACGGGAGGCAGCAG-3' (338F) and reverse 5'-GGACTACHVGGGTWTCT AAT-3' (806R) primers in the thermocycler PCR system (GeneAmp 9700, American Butter Institute, Arlington, VA, USA). PCR reactions were amplified after 3 min of denaturation at $95^{\circ} \mathrm{C}, 27$ cycles of $30 \mathrm{~s}$ at $95^{\circ} \mathrm{C}, 30 \mathrm{~s}$ for annealing at $55^{\circ} \mathrm{C}, 45 \mathrm{~s}$ for elongation at $72{ }^{\circ} \mathrm{C}$, and the final extension at $72{ }^{\circ} \mathrm{C}$ for $10 \mathrm{~min}$. PCR reactions were performed in triplicate $20 \mu \mathrm{L}$ mixture containing $4 \mu \mathrm{L}$ of $5 \times$ FastPfu Buffer ( $\mathrm{pH}$ 9.2), $2 \mu \mathrm{L}$ of $2.5 \mathrm{mM}$ dNTPs, $0.8 \mu \mathrm{L}$ of each primer $(5 \mu \mathrm{M}), 0.4 \mu \mathrm{L}$ of the FastPfu Polymerase, and $10 \mathrm{ng}$ of template DNA. PCR products were extracted from $2 \%(w / v)$ agarose gels, purified using the AxyPrep DNA Gel Extraction Kit (Axygen Biosciences, Union City, CA, USA), and quantified using QuantiFluor ${ }^{\mathrm{TM}}$-ST (Promega, Madison, WI, USA) according to the manufacturer's protocol.

Purified amplicons were pooled in equmolar quantities and paired-end sequenced $(2 \times 300)$ on an Illumina MiSeq platform (Illumina, San Diego, CA, USA) according to protocols established by the Shanghai Majorbio Bio-Pharm Technology Co. Ltd. (Shanghai, China).

The raw $16 \mathrm{~S}$ rDNA gene sequencing reads were demultiplexed, quality filtered by fastp version 0.20.0, and merged by FLASH version 1.2.7 with the following criteria: (i) the $300 \mathrm{bp}$ reads were truncated at any site receiving an average quality score of $<20$ over a $50 \mathrm{bp}$ sliding window, the truncated reads shorter than $50 \mathrm{bp}$ were discarded, and reads containing ambiguous characters were also discarded; (ii) only overlapping sequences longer than $10 \mathrm{bp}$ were assembled according to their overlapped sequence. The maximum mismatch ratio of overlap region is 0.2 . Reads that could not be assembled were discarded; (iii) samples were distinguished according to the barcode and primers, and the sequence direction was adjusted, exact barcode matching, two-nucleotide mismatch in primer matching.

Operational taxonomic units (OTUs) with $97 \%$ similarity cutoff were clustered using UPARSE version 7.1, and chimeric sequences were identified and removed. The taxonomy of each OTU representative sequence was analyzed by RDP Classifier version 2.2 against the $16 \mathrm{~S}$ rDNA database (eg. Silva v128) using a confidence threshold of 0.7 .

\subsection{Analyses of SCFAs}

The samples used for SCFAs analyses were filtered through a $0.22 \mu \mathrm{m}$ filter. Filtered supernatant, $10 \mu \mathrm{L}$, was injected into the High-Performance Liquid Chromatography System (1260, Agilent, Thuringia, Germany) equipped with a Shodex Rspak KC-811 $(8.0 \times 300 \mathrm{~mm})$ and an ultraviolet detector $(210 \mathrm{~nm})$. Eight SCFAs (lactic acid, formic acid, acetic acid, propionic acid, isobutyric acid, butyric acid, isovaleric acid, and valeric acid) were evaluated. Isocaproic acid was used as an internal standard. The eluent $\left(0.01 \% v / v \mathrm{H}_{3} \mathrm{PO}_{4}\right)$ was used at a flow rate of $0.8 \mathrm{~mL} / \mathrm{min}$.

\subsection{Histological Analyses}

Following anaesthetization, the heart, kidney, and lung were rapidly removed from rats. Tissues were weighed and fixed in $4 \%$ aqueous formalin before being snap frozen in liquid nitrogen; then, they were stored at $-80{ }^{\circ} \mathrm{C}$. The fixed tissues were embedded in paraffin, sectioned in $3 \mu \mathrm{m}$ portions with a microtome, and stained with Masson's trichrome reagent to be able to observe the collagen present in heart tissues. Perivascular and interstitial fibrosis levels were quantified in heart using the Olympus $B \times 41$ microscope (400× magnification) (Marques, et al., 2017) [17]. Collagen levels were expressed as a percentage of the area of the region using the Image-Pro Plus 6.0 (Media Cybemetics, INC., Rockville, MD, USA). 


\subsection{RNA Extraction and Cardiac Transcriptome Sequencing}

To explore the mechanism of reduction of BP and cardiac fibrosis, the cardiac transcriptome of the Vehicle, HPAO, and Captopril groups ( $n=4$ per group) were examined. Total RNA was extracted using the TRIzol ${ }^{\circledR}$ Reagent according the manufacturer's instructions (Invitrogen, Waltham, MA, USA); genomic DNA was removed using DNase I (TaKara). The RNA quality was assessed by a 2100 Bioanalyser (Agilent Technologies Inc., Palo Alto, CA, USA) and quantified using the NanoDrop 2000. The high-quality RNA sample $(\mathrm{OD} 260 / 280=1.8-2.2, \mathrm{OD} 260 / 230 \geq 2.0, \mathrm{RIN} \geq 6.5,28 \mathrm{~S}: 18 \mathrm{~S} \geq 1.0,>10 \mu \mathrm{g})$ was used to construct the sequencing library. Total RNA ( $5 \mu \mathrm{g})$ underwent mRNA enrichment using the Poly(A) mRNA magnetic isolation method. The transcriptome library was prepared with the TruSeqTM RNA sample preparation Kit for Illumina (San Diego, CA, USA). Libraries were sized according to cDNA target fragments of 200-300 bp on $2 \%(w / v)$ low-range ultra agaroses followed by PCR amplified with the Phusion DNA polymerase (NEB) for 15 PCR cycles. After DNA was quantified by the TBS380 fluorimeter (Turner Biosystem, Sunnyvale, CA, USA), the paired-end RNA-seq sequencing library was sequenced with Illumina HiSeq $4000(2 \times 150 \mathrm{bp}$ read length). RNA-seq sequencing was undertaken at the Shanghai Majorbio Bio-Pharm Technology Co. Ltd. (Shanghai, China).

\subsection{Bioinformatic Analyses}

Raw paired end reads were trimmed, and their quality was controlled by SeqPrep and Sickle. Clean reads were separately aligned to the reference genome with the orientation mode using TopHat (version 2.0.0) [56]. R statistical package software EdgeR (Empirical analysis of Digital Gene Expression in R) [57] was utilized for the differential expression analysis. GO functional enrichment and Kyoto Encyclopedia of Genes and Genomes (KEGG) pathway analyses were carried out by Goatools and KOBAS [58]. Gene Set Enrichment Analysis (GSEA) was performed using the pathways of the Natriuretic Peptide A (Nppa) gene by interrogating the KEGG databases.

\subsection{Real-Time Quantitative PCR Analyses}

The cardiac genes of Nppa were analyzed by real-time quantitative PCR (Applied Biosystems StepOnePlus ${ }^{\mathrm{TM}}$, Thermo Fisher Scientific, Waltham, MA, USA). After the rat cardiac tissues were homogenized, the total RNA was extracted as described above and reverse transcribed into cDNA with the AccuRT Genomic DNA Removal Kit (Applied Biological Materials Inc., Vancouver, BC, Canada). Real-time quantitative PCR was performed with the Eva Green 2× qPCR MasterMix (Applied Biological Materials Inc., Vancouver, BC, Canada). The amount of target RNA was normalized to the amount of endogenous GAPDH control, and the results were given by $2^{-\Delta \Delta C T}$ relative to the control sample. Primers used in the amplification reaction were forward: $5^{\prime}$-CGGAAGCTGTTGCAGCCTA-3' and reverse: 5'-GCCCTG AGCGAGCAGACCGA-3'.

\subsection{Statistical Analysis}

The GraphPad Prism (version 5) package and origin packages (version 9.0) were used for generating graphs. One-way ANOVA for multiple comparisons was used to compare the Vehicle and HPAO, LPAO, $\mathrm{KCl}$, and Captopril groups. All data are presented as mean \pm SD or mean \pm SEM; those with a $p<0.05$ were considered statistically significant.

\section{Conclusions}

This study suggests that PAO could lower BP and improve the development of HF in SHR by modulating GM, such as reducing the ratio of Firmicutes to Bacteroidetes, the relative abundance of Prevotella, Phascolarctobacterium, and decreasing the plasma levels of LPS metabolites produced by the Gram-negative bacteria. PAO could regulate the expression of Nppa gene, ANP, and AngII levels in plasma, thus protecting the cardiac function. PAO has great potential in HTN therapy. 
Supplementary Materials: The following are available online at https://www.mdpi.com/article/10 $.3390 /$ ijms22189823/s1.

Author Contributions: Conceptualization, Z.-L.H. and H.-J.M.; Methodology, Z.-L.H. and H.-J.M.; Experimental work, Z.-L.H., M.Y., X.-D.F. and M.C.; Analysis of the results, Z.-L.H. and M.C.; Writing-Original Draft Preparation, Z.-L.H.; Writing-Review and Editing, M.H., Y.-H.Z. and H.-J.M. All authors have read and agreed to the published version of the manuscript.

Funding: This work was supported by the National Natural Science Foundation of China (31872893), the Key Research and Development Project Foundation of Shandong Province (2017YYSP003) and the Shandong Natural Science Fund (ZR2017MD006).

Institutional Review Board Statement: The animal study was approved by the Committee on the Ethics of Animal Experiments of Ocean University of China (Approved protocol ID SCKK 2016-0011).

Data Availability Statement: The data are available from the corresponding author on reasonable request.

Acknowledgments: The author wishes to thank Changliang Zhu for animal care and also Dan Dong and Yan Yan for the proofreading of the manuscript.

Conflicts of Interest: The authors declare that they have no conflict of interest.

\section{References}

1. Strandberg, T.E. Blood pressure in a 100-Year perspective. Circulation 2019, 140, 101-102. [CrossRef] [PubMed]

2. Kearney, P.M.; Whelton, M.; Reynolds, K.; Muntner, P.; Whelton, P.K.; He, D.J. Global burden of hypertension: Analysis of worldwide data. Lancet 2005, 365, 217-223. [CrossRef]

3. Mozaffarian, D.; Benjamin, E.J.; Go, A.S.; Arnett, D.K.; Blaha, M.J.; Cushman, M.; Das, S.R.; de Ferranti, S.; Després, J.P.; Fullerton, H.J.; et al. Heart disease and stroke statistics-2016 update: A report from the American Heart Association. Circulation 2016, 133, e38-e360. [CrossRef] [PubMed]

4. Yang, G.; Wang, Y.; Zeng, Y.; Gao, G.F.; Liang, X.; Zhou, M.; Wan, X.; Yu, S.; Jiang, Y.; Naghavi, M.; et al. Rapid health transition in China, 1990-2010: Findings from the Global Burden of Disease Study 2010. Lancet 2013, 381, 1987-2015. [CrossRef]

5. Mills, K.T.; Bundy, J.D.; Kelly, T.N.; Reed, J.E.; Kearney, P.M.; Reynolds, K.; Chen, J.; He, J. Global disparities of hypertension prevalence and control: A systematic analysis of population-based studies from 90 countries. Circulation 2016, 134, 441-450. [CrossRef] [PubMed]

6. Ueno, M.; Tamura, Y.; Toda, N.; Yoshinaga, M.; Terakado, S.; Otsuka, K.; Numabe, A.; Kawabata, Y.; Murota, I.; Sato, N.; et al. Sodium alginate oligosaccharides attenuate hypertension in spontaneously hypertensive rats fed a low-salt diet. Clin. Exp. Hypertens. 2012, 34, 305-310. [CrossRef]

7. Moriya, C.; Shida, Y.; Yamane, Y.; Miyamoto, Y.; Kimura, M.; Huse, N.; Ebisawa, K.; Kameda, Y.; Nishi, A.; Du, D.; et al. Subcutaneous administration of sodium alginate oligosaccharides prevents salt-induced hypertension in Dahl salt-sensitive rats. Clin. Exp. Hypertens. 2013, 35, 607-613. [CrossRef]

8. Chen, Y.Y.; Ji, W.; Du, J.R.; Yu, D.K.; He, Y.; Yu, C.X.; Li, D.S.; Zhao, C.Y.; Qiao, K. Preventive effects of low molecular mass potassium alginate extracted from brown algae on DOCA salt-induced hypertension in rats. Biomed. Pharmacother. 2010, 64, 291-295. [CrossRef]

9. Shang, Q.; Jiang, H.; Cai, C.; Hao, J.; Li, G.; Yu, G. Gut microbiota fermentation of marine polysaccharides and its effects on intestinal ecology: An overview. Carbohydr. Polym. 2018, 179, 173-185. [CrossRef]

10. Zeller, G.; Tap, J.; Voigt, A.Y.; Sunagawa, S.; Kultima, J.R.; Costea, P.I.; Amiot, A.; Böhm, J.; Brunetti, F.; Habermann, N.; et al. Potential of fecal microbiota for early-stage detection of colorectal cancer. Mol. Syst. Biol. 2014, 10, 766.

11. Qin, N.; Yang, F.; Li, A.; Prifti, E.; Chen, Y.; Shao, L.; Guo, J.; Le Chatelier, E.; Yao, J.; Wu, L.; et al. Alterations of the human gut microbiome in liver cirrhosis. Nature 2014, 513, 59-64. [CrossRef]

12. Scher, J.U.; Sczesnak, A.; Longman, R.S.; Segata, N.; Ubeda, C.; Bielski, C.; Rostron, T.; Cerundolo, V.; Pamer, E.G.; Abramson, S.B.; et al. Expansion of intestinal Prevotella copri correlates with enhanced susceptibility to arthritis. Elife 2013, 2, e01202. [CrossRef]

13. Qin, J.; Li, Y.; Cai, Z.; Li, S.; Zhu, J.; Zhang, F.; Liang, S.; Zhang, W.; Guan, Y.; Shen, D.; et al. A metagenome-wide association study of gut microbiota in type 2 diabetes. Nature 2012, 490, 55-60. [CrossRef] [PubMed]

14. Karlsson, F.H.; Fåk, F.; Nookaew, I.; Tremaroli, V.; Fagerberg, B.; Petranovic, D.; Bäckhed, F.; Nielsen, J. Symptomatic atherosclerosis is associated with an altered gut metagenome. Nat. Commun. 2012, 3, 1245. [CrossRef]

15. Yang, T.; Santisteban, M.M.; Rodriguez, V.; Li, E.; Ahmari, N.; Carvajal, J.M.; Zadeh, M.; Gong, M.; Qi, Y.; Zubcevic, J.; et al. Gut dysbiosis is linked to hypertension. Hypertension 2015, 65, 1331-1340. [CrossRef]

16. Mell, B.; Jala, V.R.; Mathew, A.V.; Byun, J.; Waghulde, H.; Zhang, Y.; Haribabu, B.; Vijay-Kumar, M.; Pennathur, S.; Joe, B. Evidence for a link between gut microbiota and hypertension in the Dahl rat. Physiol. Genom. 2015, 47, 187-197. [CrossRef] [PubMed]

17. Li, J.; Zhao, F.; Wang, Y.; Chen, J.; Tao, J.; Tian, G.; Wu, S.; Liu, W.; Cui, Q.; Geng, B.; et al. Gut microbiota dysbiosis contributes to the development of hypertension. Microbiome 2017, 5, 14. [CrossRef] 
18. Marques, F.Z.; Nelson, E.; Chu, P.Y.; Horlock, D.; Fiedler, A.; Ziemann, M.; Tan, J.K.; Kuruppu, S.; Rajapakse, N.W.; El-Osta, A.; et al. High-fiber diet and acetate supplementation change the gut microbiota and prevent the development of hypertension and heart failure in hypertensive mice. Circulation 2017, 135, 964-997. [CrossRef] [PubMed]

19. Hidalgo, M.; Prieto, I.; Abriouel, H.; Villarejo, A.B.; Ramírez-Sánchez, M.; Cobo, A.; Benomar, N.; Gálvez, A.; Martínez-Cañamero, $\mathrm{M}$. Changes in gut microbiota linked to a reduction in systolic blood pressure in spontaneously hypertensive rats fed an extra virgin olive oil-enriched diet. Plant. Foods Hum. Nutr. 2018, 73, 1-6. [CrossRef]

20. Yang, T.; Aquino, V.; Lobaton, G.O.; Li, H.; Colon-Perez, L.; Goel, R.; Qi, Y.; Zubcevic, J.; Febo, M.; Richards, E.M.; et al. Sustained captopril-induced reduction in blood pressure is associated with alterations in gut-brain axis in the spontaneously hypertensive rat. J. Am. Heart Assoc. 2019, 8, e010721. [CrossRef]

21. FitzGerald, R.J.; Murray, B.A.; Walsh, D.J. Hypotensive peptides from milk proteins. J. Nutr. 2004, 134, 980S-988S. [CrossRef]

22. Sanz, Y.; Moya-Pérez, A. Microbiota, Inflammation and obesity. In Microbial Endocrinology: The Microbiota-Gut-Brain Axis in Health and Disease; Lyte, M., Cryan, J., Eds.; Springer: New York, NY, USA, 2014; Volume 817, pp. 291-317.

23. Li, L.; Xue, C.H.; Zhang, T.T.; Wang, Y.M. The interaction between dietary marine components and intestinal flora. Mar. Life Sci. Technol. 2020, 2, 161-171. [CrossRef]

24. Zhang, P.; Liu, J.; Xiong, B.; Zhang, C.; Kang, B.; Gao, Y.; Li, Z.; Ge, W.; Cheng, S.; Hao, Y.; et al. Microbiota from alginate oligosaccharide-dosed mice successfully mitigated small intestinal mucositis. Microbiome 2020, 8, 1-15. [CrossRef]

25. Wang, Y.; Li, L.; Ye, C.; Yuan, J.; Qin, S. Alginate oligosaccharide improves lipid metabolism and inflammation by modulating gut microbiota in high-fat diet fed mice. Appl. Microbiol. Biotechnol. 2020, 104, 3541-3554. [CrossRef] [PubMed]

26. Han, Z.L.; Yang, M.; Fu, X.D.; Chen, M.; Su, Q.; Zhao, Y.H.; Mou, H.J. Evaluation of prebiotic potential of three marine algae oligosaccharides from enzymatic hydrolysis. Mar. Drugs 2019, 17, 173. [CrossRef]

27. Adnan, S.; Nelson, J.W.; Ajami, N.J.; Venna, V.R.; Petrosino, J.F.; Bryan, R.M., Jr.; Durgan, D.J. Alterations in the gut microbiota can elicit hypertension in rats. Physiol. Genom. 2017, 49, 96-104. [CrossRef] [PubMed]

28. Segura, A.M.; Frazier, O.H.; Buja, L.M. Fibrosis and heart failure. Heart Fail. Rev. 2014, 19, 173-185. [CrossRef] [PubMed]

29. Chien, K.R.; Knowlton, K.U.; Zhu, H.; Chien, S. Regulation of cardiac gene expression during myocardial growth and hypertrophy: Molecular studies of an adaptive physiologic response. FASEB J. 1991, 5, 3037-3046. [CrossRef]

30. Zhang, H.; Mo, X.; Qian, Q.; Zhou, Z.; Zhu, Z.; HuangFu, X.; Xu, T.; Wang, A.; Guo, Z.; Zhang, Y. Associations among NPPA gene polymorphisms, serum ANP levels, and hypertension in the Chinese Han population. J. Hum. Hypertens. 2019, 33, 641-647. [CrossRef]

31. Schmitt, M.; Cockcroft, J.R.; Frenneaux, M.P. Modulation of the natriuretic peptide system in heart failure: From bench to bedside? Clin. Sci. 2003, 105, 141-160. [CrossRef]

32. Long, D.A.; Kolatsi-Joannou, M.; Price, K.L.; Dessapt-Baradez, C.; Huang, J.L.; Papakrivopoulou, E.; Hubank, M.; Korstanje, R.; Gnudi, L.; Woolf, A.S. Albuminuria is associated with too few glomeruli and too much testosterone. Kidney Int. 2013, 83, 1118-1129. [CrossRef]

33. Oei, G.T.; Heger, M.; van Golen, R.F.; Alles, L.K.; Flick, M.; van der Wal, A.C.; van Gulik, T.M.; Hollmann, M.W.; Preckel, B.; Weber, N.C. Reduction of cardiac cell death after helium postconditioning in rats: Transcriptional analysis of cell death and survival pathways. Mol. Med. 2015, 20, 516-526. [CrossRef]

34. Juang, Y.L.; Jeng, Y.M.; Chen, C.L.; Lien, H.C. PRRX2 as a novel TGF- $\beta$-induced factor enhances invasion and migration in mammary epithelial cell and correlates with poor prognosis in breast cancer. Mol. Carcinog. 2016, 55, 2247-2259. [CrossRef] [PubMed]

35. Sadahiro, T.; Isomi, M.; Muraoka, N.; Kojima, H.; Haginiwa, S.; Kurotsu, S.; Tamura, F.; Tani, H.; Tohyama, S.; Fujita, J.; et al. Tbx6 Induces Nascent Mesoderm from Pluripotent Stem Cells and Temporally Controls Cardiac versus Somite Lineage Diversification Cell Stem Cell 2018, 23, 382-395. [CrossRef]

36. Yu, D.; Shi, M.; Bao, J.; Yu, X.; Li, Y.; Liu, W. Genipin ameliorates hypertension-induced renal damage via the angiotensin II-TLR/MyD88/MAPK pathway. Fitoterapia 2016, 112, 244-253. [CrossRef]

37. Zhao, D.; Wang, W.; Wang, H.; Peng, H.; Liu, X.; Guo, W.; Su, G.; Zhao, Z. PKD knockdown inhibits pressure overload-induced cardiac hypertrophy by promoting autophagy via AKT/mTOR pathway. Int. J. Biol. Sci. 2017, 13, 276-285. [CrossRef] [PubMed]

38. Wang, J.; Knaut, H. Chemokine signaling in development and disease. Development 2014, 141, 4199-4205. [CrossRef]

39. Durgan, D.J.; Ganesh, B.P.; Cope, J.L.; Ajami, N.J.; Phillips, S.C.; Petrosino, J.F.; Hollister, E.B.; Bryan, R.M., Jr. Role of the gut microbiome in obstructive sleep apnea-induced hypertension. Hypertension 2016, 67, 469-474. [CrossRef]

40. Vasdev, S.; Ford, C.A.; Parai, S.; Longerich, L.; Gadag, V. Dietary alpha-lipoic acid supplementation lowers blood pressure in spontaneously hypertensive rats. J. Hypertens. 2000, 18, 567-573. [CrossRef]

41. Sola, S.; Mir, M.Q.; Cheema, F.A.; Khan-Merchant, N.; Menon, R.G.; Parthasarathy, S.; Khan, B.V. Irbesartan and lipoic acid improve endothelial function and reduce markers of inflammation in the metabolic syndrome: Results of the Irbesartan and Lipoic Acid in Endothelial Dysfunction (ISLAND) study. Circulation 2005, 111, 343-348. [CrossRef]

42. Guo, J.J.; Xu, F.Q.; Li, Y.H.; Li, J.; Liu, X.; Wang, X.F.; Hu, L.G.; An, Y. Alginate oligosaccharide alleviates myocardial reperfusion injury by inhibiting nitrative and oxidative stress and endoplasmic reticulum stress-mediated apoptosis. Drug Des. Dev. Ther. 2017, 11, 2387-2397. [CrossRef]

43. Bubb, K.J.; Trinder, S.; Baliga, R.S.; Patel, J.; Clapp, L.H.; Macallister, R.J.; Hobbs, A.J. Inhibition of Phosphodiesterase 2 Augments cGMP and cAMP Signaling to Ameliorate Pulmonary Hypertension. Circulation 2014, 130, 496-507. [CrossRef] 
44. Sucharov, C.C.; Nakano, S.J.; Slavov, D.; Schwisow, J.A.; Rodriguez, E.; Nunley, K.; Medway, A.; Stafford, N.; Nelson, P.; McKinsey, T.A.; et al. A PDE3A promoter polymorphism regulates cAMP-induced transcriptional activity in failing human myocardium. $J$. Am. Coll. Cardiol. 2019, 73, 1173-1184. [CrossRef]

45. Brandes, R.P. Endothelial dysfunction and hypertension. Hypertension 2014, 64, 924-928. [CrossRef]

46. Wong, P.C.; Guo, J.; Zhang, A. The renal and cardiovascular effects of natriuretic peptides. Adv. Physiol. Educ. 2017, 41, 179-185. [CrossRef]

47. Soualmia, H.; Barthélemy, C.; Eurin, J.; Masson, F.; Carayon, A. Role of nitric oxide on atrial natriuretic peptide release induced by angiotensin II in superfused rat atrial tissue. Regul. Pept. 2001, 98, 105-110. [CrossRef]

48. Sorescu, D. Smad3 mediates angiotensin II- and TGF-beta1-induced vascular fibrosis: Smad3 thickens the plot. Cir. Res. 2006, 98, 988-989. [CrossRef]

49. Mushtaq, N.; Hussain, S.; Zhang, S.; Yuan, L.; Li, H.; Ullah, S.; Wang, Y.; Xu, J. Molecular characterization of alterations in the intestinal microbiota of patients with grade 3 hypertension. Int. J. Mol. Med. 2019, 44, 513-522. [CrossRef] [PubMed]

50. Santisteban, M.M.; Qi, Y.F.; Zubcevic, J.; Kim, S.; Yang, T.; Shenoy, V.; Cole-Jeffrey, C.T.; Lobaton, G.; Stewart, D.C.; Rubiano, A.; et al. Hypertension-Linked Pathophysiological Alterations in the Gut. Circ. Res. 2017, 120, 312-323. [CrossRef]

51. Verhaar, B.J.H.; Prodan, A.; Nieuwdorp, M.; Muller, M. Gut Microbiota in Hypertension and Atherosclerosis: A Review. Nutrients 2020, 12, 2982. [CrossRef] [PubMed]

52. Wang, Z.; Zhao, Y. Gut microbiota derived metabolites in cardiovascular health and disease. Protein Cell $2018,9,416-431$. [CrossRef] [PubMed]

53. Bartolomaeus, H.; Balogh, A.; Yakoub, M.; Homann, S.; Markó, L.; Höges, S.; Tsvetkov, D.; Krannich, A.; Wundersitz, S.; Avery, E.G.; et al. Short-Chain Fatty Acid Propionate Protects from Hypertensive Cardiovascular Damage. Circulation 2019, 139, 1407-1421. [CrossRef]

54. Wu, D.; Tang, X.; Ding, L.; Cui, J.; Wang, P.; Du, X.; Yin, J.; Wang, W.; Chen, Y.; Zhang, T. Candesartan attenuates hypertensionassociated pathophysiological alterations in the gut. Biomed. Pharmacother. 2019, 116, 109040. [CrossRef] [PubMed]

55. Verhaar, B.J.H.; Collard, D.; Prodan, A.; Levels, J.H.M.; Zwinderman, A.H.; Bäckhed, F.; Vogt, L.; Peters, M.J.L.; Muller, M.; Nieuwdorp, M.; et al. Associations between gut microbiota, faecal short-chain fatty acids, and blood pressure across ethnic groups: The HELIUS study. Eur. Heart J. 2020, 41, 4259-4267. [CrossRef] [PubMed]

56. Robinson, M.D.; McCarthy, D.J.; Smyth, G.K. EdgeR: A bioconductor package for differential expression analysis of digital gene expression data. Bioinformatics 2010, 26, 139-140. [CrossRef]

57. Trapnell, C.; Pachter, L.; Salzberg, S.L. TopHat: Discovering splice junctions with RNA-Seq. Bioinformatics 2009, $25,1105-1111$. [CrossRef]

58. Xie, C.; Mao, X.; Huang, J.; Ding, Y.; Wu, J.; Dong, S.; Kong, L.; Gao, G.; Li, C.Y.; Wei, L. KOBAS 2.0: A web server for annotation and identification of enriched pathways and diseases. Nucleic Acids Res. 2011, 39, W316-W322. [CrossRef] 